\title{
PSYCHE
}

\section{THE ENTOMOLOGICAL WORK OF DR. A. S. PACKARD.}

BY JOHN B. SMITH. SC. D.

Very few persons realize the extent or appreciate the character and value of the entomological work done by Dr. A. S. Packard. Not the systematist purely, for he will find much of the work superseded, not accepted, or so generally accepted that the original author is no longer recognized; not the entomotomist purely, for he will recognize only the specific result obtained and not the bearing of that result which Dr. Packard had usually in mind in his anatomical investigations; and surely not the modern economic entomologist, for he has now advanced far beyond any point ever reached by our author.

It is only within the past year or two, when it became necessary for me to study rather closely an almost complete series of his writings, that I began to appreciate the volume and general high standard of Dr. Packard's works. They illustrate a marvelous comprehension of the subject as a whole, a grasp of detail in many groups that is astonishing, and a knowledge of the literature that is surprising when its scattered condition and the variety of languages in which it appeared, is considered.

Dr. Packard was both an investigator and a teacher: as a teacher in the class room or in the laboratory I know nothing of him; as a teacher through books he has taught more students than any other American Entomologist. He was not a writer of numerous short papers, of hasty criticisms or of single descriptions; and yet his publications were many, some of them brief and many critical; but all had a purpose - the conveyance of knowledge or the correction of error - the correction always made without reflecting upon the honesty or capacity of him who made it necessary. Not that Dr. Packard made no errors himself: no one was more ready than he to recognize his liability in that direction, and he was not ashamed to admit it. Not infrequently he changed his conclusions, and when we compare the first edition of the Guide, with the "Text Book," the full extent of the revision of such conclusions becomes apparent.

As a systematist Dr. Packard was interested primarily in the general arrangement of the Class, and he was among the first if not the first American that accepted the necessity of breaking up some of the Linnaean orders and proposed a 
system of his own as a substitute. Some of his suggestions mat with approval, others did not; but in all instances there was at least a plausible case and some actual characters to maintain it. The discussion was always informing, if not always convincing.

In almost every order Dr. Packard did some systematic work or discussed some point in classification: in the Lepidoptera he produced the only comprehensive illustrated revision of any family of considerable extent that has yet appeared in the United States. The Monograph of the Geometridae is as complete as it was possible to make it at the time. Material was secured from all available sources, all the literature was collated and each species was as completely made known as the conditions permitted. But it was not only a species mill: the structure of the insects was elucidated, their relationships were discussed and numerous figures illustrate the discussion. As a piece of systematic work the monograph has its faults; we see them now because of added knowledge and materiai:-the classification has been largely superseded; but that is the fate of all classifications: there were errors of synonymy of association and of many other divers characters; they have been corrected and the work still stands, useful as ever as a record of facts and as an illustration of the stage of knowledge at the time it was written.

Dr. Packard studied the philosophy of individual insect development from the very beginning as a necessary preliminary to the discussion of the development of the class; hence we find that he was as much at home in ontogeny as in phylogeny, and nowhere is that better illustrated than in the Text Book of Entomology, published by the MacMillan Company in 1898 . There is scarcely a topic in that Book to which there is not some original contribution or some reference which indicates that there was actual knowledge and not mere quotation. And this brings up again the wide familiarity with the literature on insect structures and development; most of it printed in foreign countries or Journais, and such of it as is American, scattered in Proceedings, Transactions and Journals of the most diverse kinds. In bringing together and systematizing this mass of material Dr. Packard has rendered a service to Entomological Science which Entomologists have hardly, as yet appreciated. Some of his conclusions are disputed and may be erroneous; but the facts are given and if the expressed convictions are formed on insufficient evidence, time will enable us to make the corrections.

In the line of economic work Dr. Packard was for a time associated with Drs. C. V. Riley and Cyrus Thomas on the Entomological Commission. He contributed to nearly all the reports; but less to the strictly economic subject than to a discussion of principles and to some work on structural characters which may or 
may not have been entirely pertinent. Yet his connection with the economic side of the study extends back to $187 \mathrm{I}$, the date of his first report on the injurious and beneficial insects of Massachusetts; and even before that he had written on the subject.

The most important contribution in this branch is the Volume on Forest Insects, published as one of the Reports of the Entomological Commission. This exhibits very strongly the painstaking method of gathering all recorded facts and of securing information from all possible sources. As a record of what is known or has been written concerning insects feeding on forest trees in the United States it is a most useful work. The weak point is the absence of a general scheme of remedial measures or forest management which may be applied with necessary modifications in special instances, to lessen or prevent injury.

Dr. Packard, while not without considerable experience in field work, was not a good field collector and observer of habits, and certainly not a good museum preparator. He was essentially a student of specimens, living and dead and of the phenomena exhibited by them.

I will make no attempt to give even a partial list of his more important works: it will suffice to say that the student who is entirely familiar with what Dr. Packard has written is, by virtue of that knowledge alone, a good entomologist. 


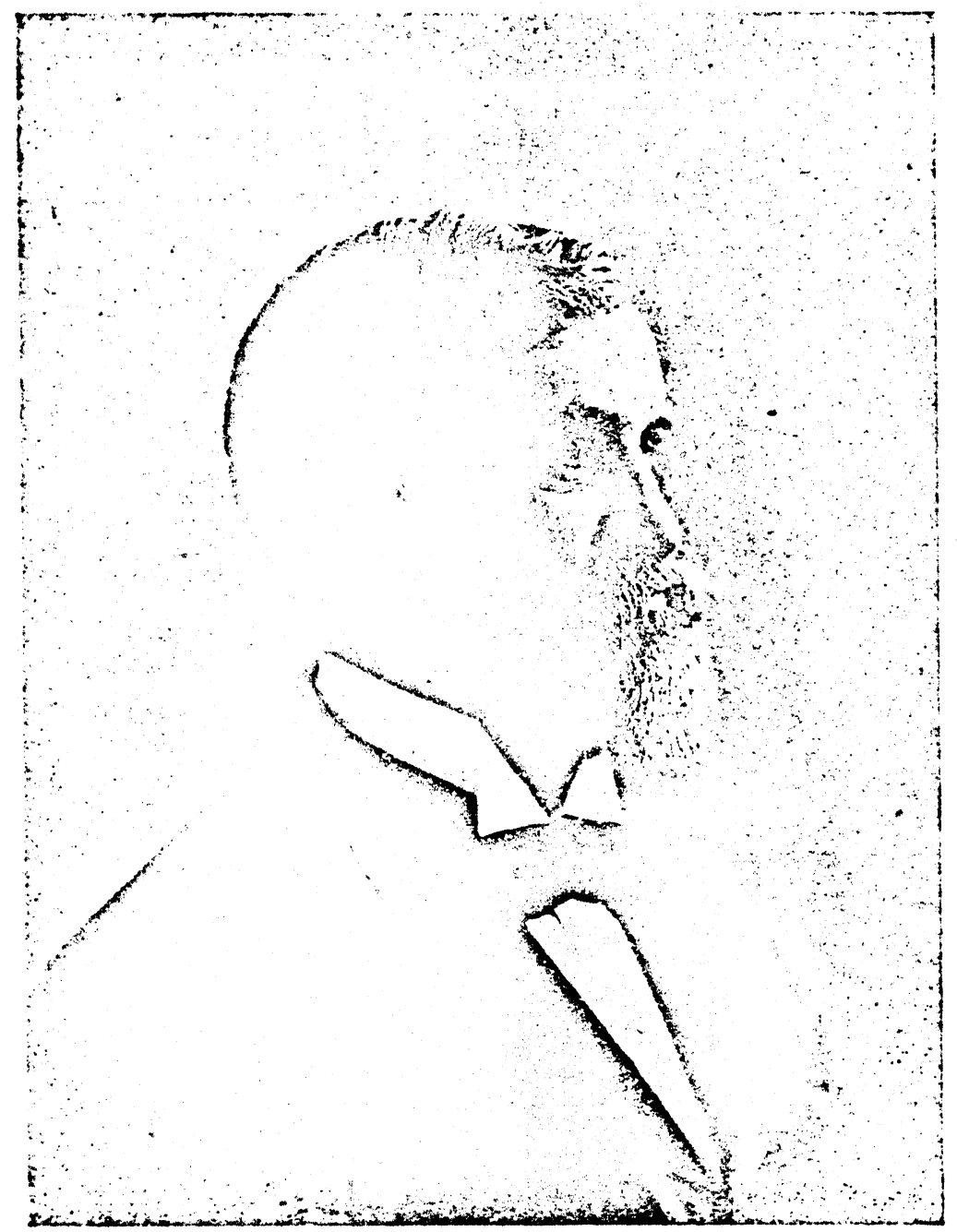



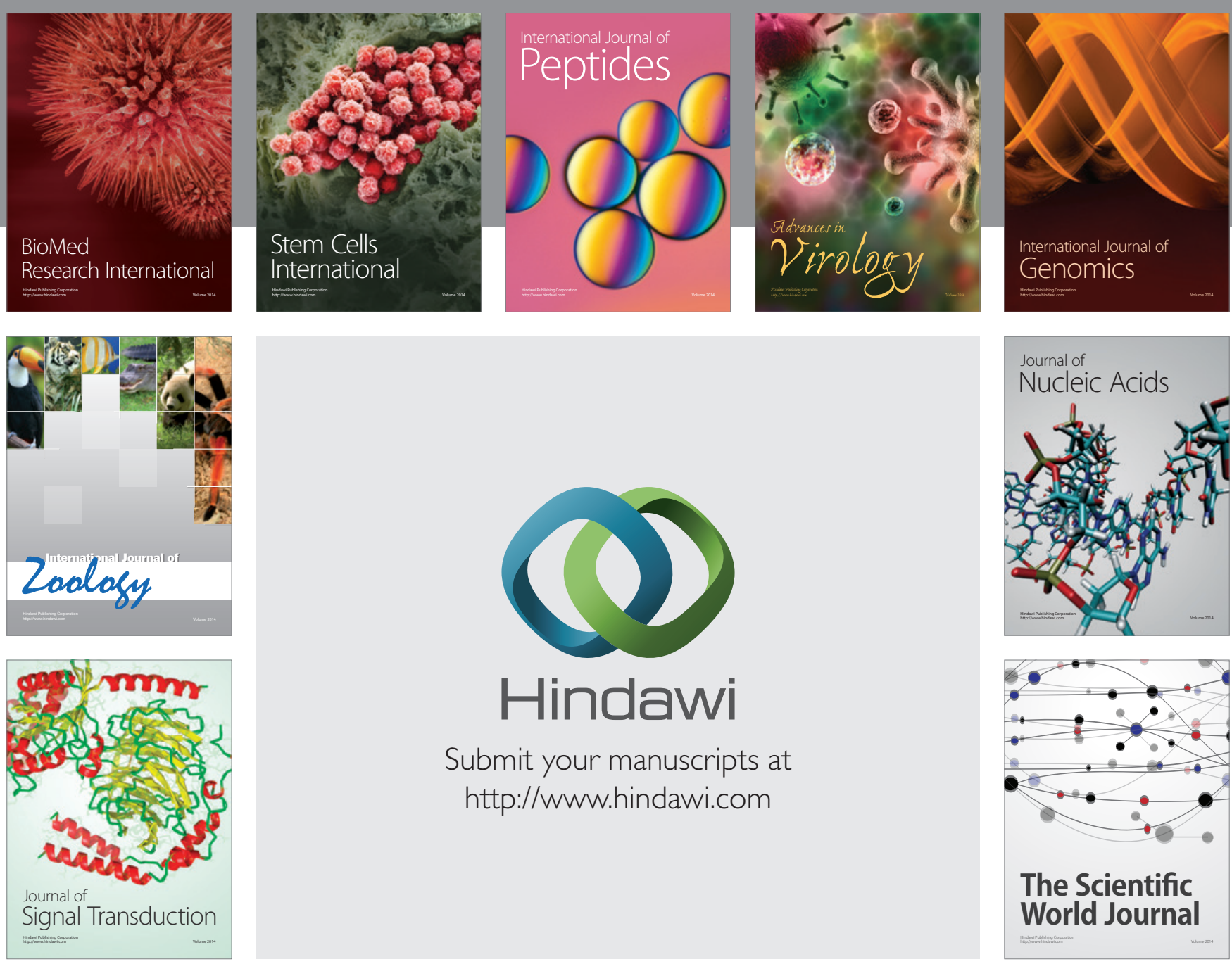

Submit your manuscripts at

http://www.hindawi.com
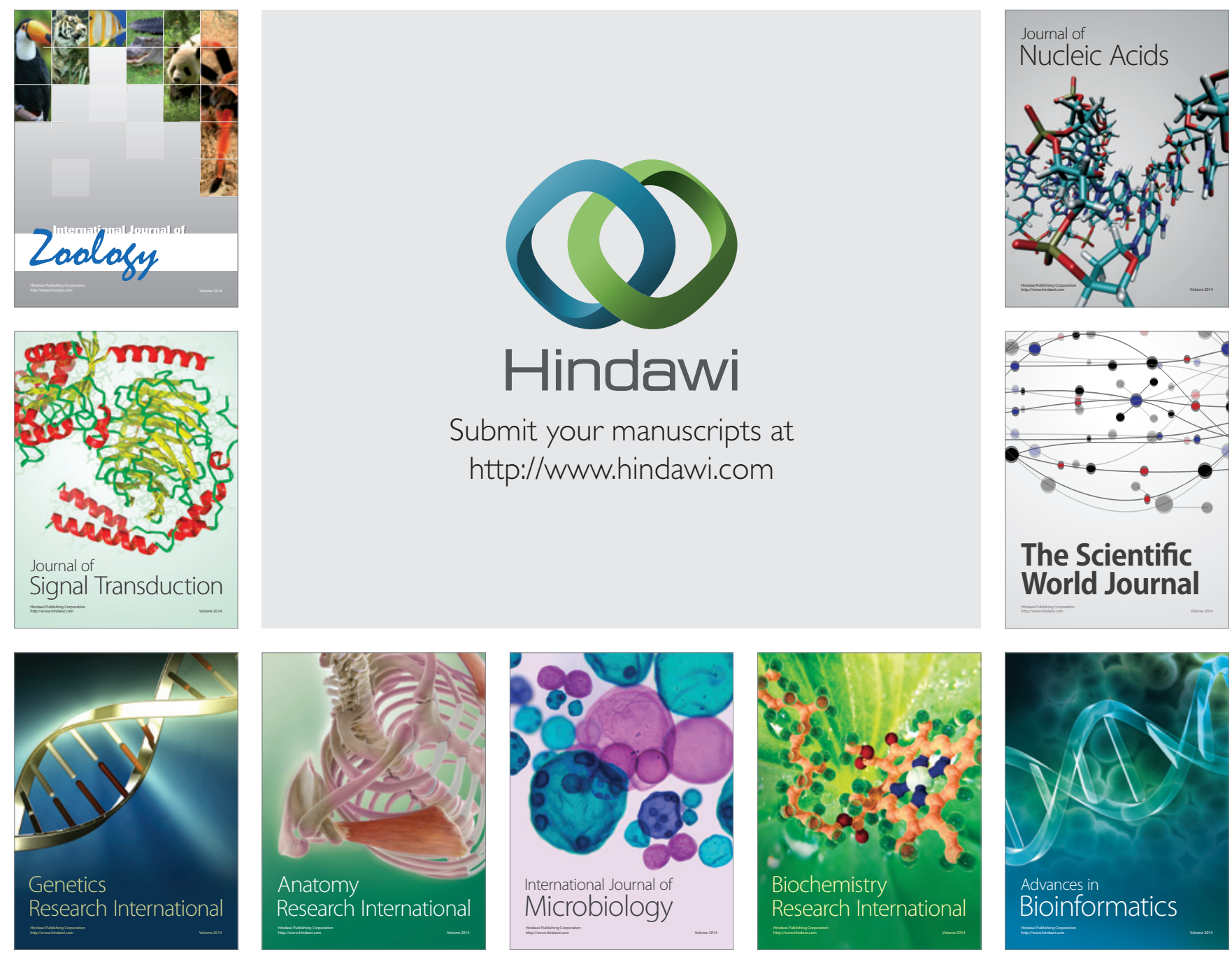

The Scientific World Journal
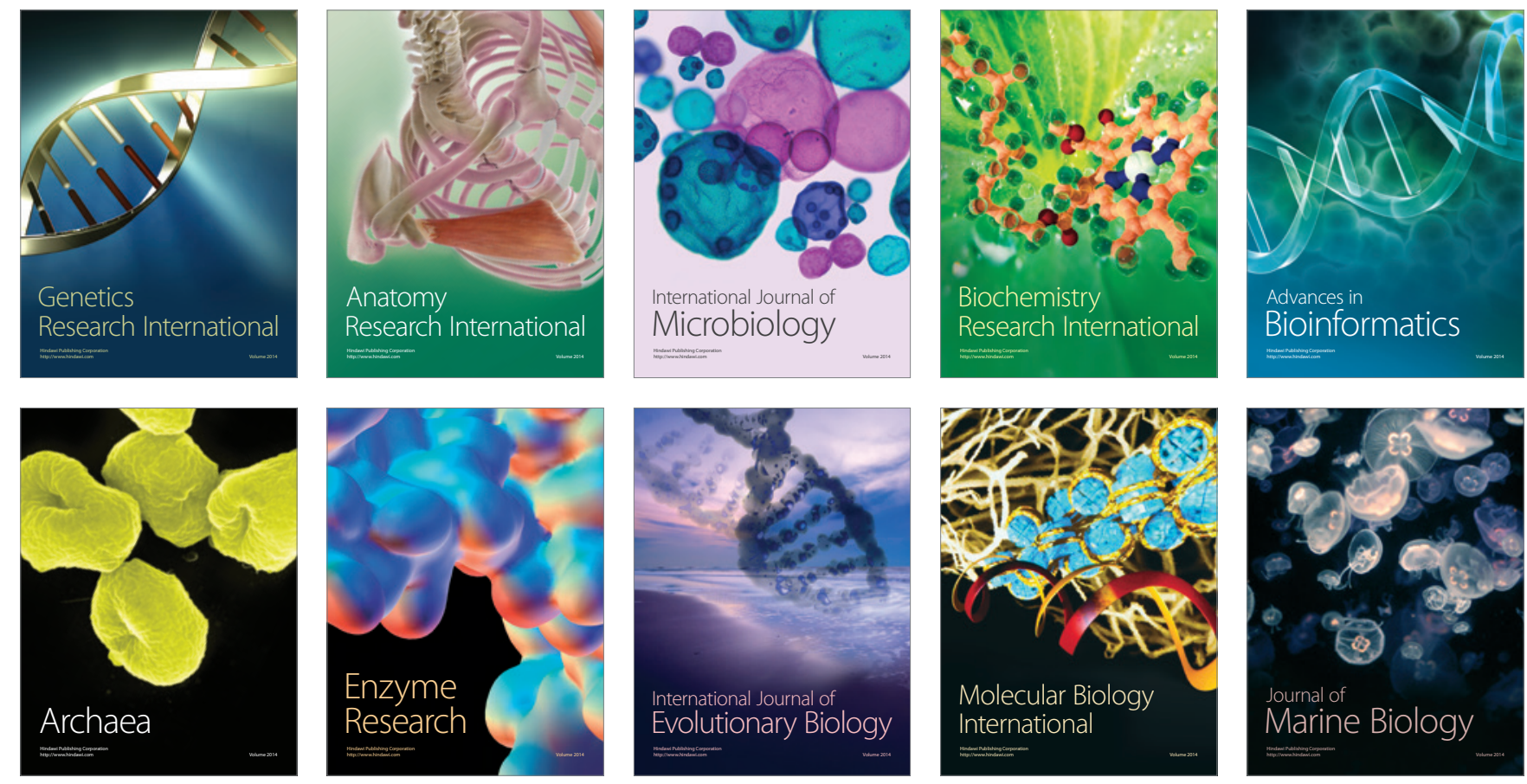